\title{
O ABRIGAMENTO E AS REDES DE PROTEÇÃo PARA A INFÂNCIA E A JUVENTUDE
}

\author{
Lygia Santa Maria Ayres \\ Ana Paula Cardoso $\star$ \\ Livia Cretton Pereira ${ }^{\star \star \star}$
}

\begin{abstract}
Resumo
A partir de uma pesquisa acerca de produções acadêmicas referentes à temática abrigamento, objetivando cartografar subjetividades construídas dentro de abrigos, analisamos textos (livros, artigos, dissertações e teses), no período de 2000 a 2008 referentes a essa temática. Debruçamo-nos sobre esse material com a finalidade de dar visibilidade aos discursos/práticas que estão sendo produzidos, traçando um breve histórico das medidas de assistência e proteção à infância e à juventude brasileiras. A partir do conteúdo dos textos foram levantadas diferentes categorias de análise, porém aqui estamos priorizando os debates relativos a uma delas: "Rede de Assistência ao Abrigo". Tomando o referencial da Análise do Discurso, o presente artigo problematiza as redes de proteção das políticas públicas de garantia dos direitos da criança e do adolescente. Constatamos que, grande parte dos textos estudados mencionava a fragilidade das redes de proteção como responsáveis pela permanência de crianças e adolescentes em abrigos.

Palavras-chave: políticas públicas; redes de proteção; abrigamento.

\section{THE SHELTER AND THE NETWORK OF SHELTER ASSISTANCE OF CHILDREN AND ADOLESCENTS}

\begin{abstract}
:
From a research on academic productions related to housing issues, aiming to map subjectivities constructed in shelters, we analyzed texts (books, articles, theses and dissertations) about the issue from the period between 2000 and 2008. We

^ Psicóloga do Serviço de Psicologia Aplicada (SPA) da Universidade Federal Fluminense (UFF), pesquisadora e coordenadora do Programa de Intervenção Voltado às Engrenagens e Territórios de Exclusão social (PIVETES). Endereço: Universidade Federal Fluminense, Serviço de Psicologia Aplicada (SPA), Campus do Gragoatá - Rua Professor Marcos Waldemar de Freitas Reis, Bloco N, $5^{\circ}$ andar. São Domingos - Niterói. CEP 24210-201 - RJ - Brasil E-mail: lygia.ayres@gmail.com

$\star \star$ Estudante da graduação em psicologia pela Universidade Federal Fluminense (UFF), bolsista de iniciação científica da Faperj através do Programa de Intervenção Voltado às Engrenagens e Territórios de Exclusão social (PIVETES).

$\star \star \star$ Estudante da graduação em psicologia pela Universidade Federal Fluminense (UFF), pesquisadora do Programa de Intervenção Voltado às Engrenagens e Territórios de Exclusão social (PIVETES).
\end{abstract}


studied the material carefully in order to give visibility to the discourses and practices that are being produced, outlining a brief history of assistance and protection measures to children and youth in Brazil. From the content of the texts were raised different categories of analysis, but here we have decided to focus on the discussions about one of them: "Network of Shelter Assistance". Taking the reference of the Speech Analysis, this article analyses the protection networks from the public policies which guarantee the rights of children and adolescents. We noticed that most studied texts mentioned the fragility of these networks as responsible for the protection and retention of children and adolescents in shelters.

Keywords: public policies; protection networks; shelter.

\section{INTRODUÇão}

$\mathrm{O}$ relato que apresentamos aqui diz respeito à pesquisa bibliográfica "Cenários dos Abrigos no Brasil: uma leitura a partir de produções acadêmicas" ", que levantou textos acadêmicos tais como artigos, livros, teses, dissertações e monografias datados entre 2000 a 2008, escolhido por tratar-se de um período pós-promulgação do Estatuto da Criança e do Adolescente (ECA). Tais produções escritas foram selecionadas a partir dos temas abrigo, abandono, convivência familiar, sendo buscadas em portais, sites de consultas bibliográficas e bibliotecas virtuais e físicas.

O encontro com esses textos nos possibilitou perceber que grande parte dos artigos estudados mencionava a fragilidade das redes de proteção à infância como sendo responsáveis pela permanência de muitas crianças e adolescentes em abrigos. Tendo como referencial as ferramentas da pesquisa-intervenção (BARROS, 2007), trabalhamos com uma análise coletiva das obras levantadas, em que todos os integrantes da pesquisa participaram das leituras e conseqüente análise e retirada das categorias das obras consultadas. A busca, leitura e discussão dos textos foram concomitantes, isto é, esta pesquisa não coletou primeiro os dados e depois os analisou, não havendo, portanto, uma linearidade em seu percurso, mas sim, um campo em permanente construção. Este mecanismo possibilitou que o pesquisador ao longo das investigações sobre o tema fosse envolvido de forma a potencializar suas ferramentas de análise, criando novas formas no manejo do trabalho.

A partir da leitura do material recolhido, foram propostas algumas categorias de análise, localizando temas que estão sendo pesquisados nesse campo e o que tem sido dito a respeito de crianças e adolescentes abrigados no Brasil. Do conjunto de categorias, uma delas, "Redes de Proteção à crianças e adolescentes", problematiza as redes de proteção e os discursos dos especialistas acerca das políticas públicas no que tange à garantia dos direitos da criança e do adolescente.

Debruçamo-nos sobre essa temática com a finalidade de colocar em análise os efeitos dos discursos produzidos pelos especialistas nas práticas cotidianas de assistência à infância e adolescência, e de que forma os mesmos foram construin- 
do modos distintos de lidar com tal questão a cada período histórico. O discurso é aqui pensado enquanto prática social, ou seja, produz modos de funcionamento e gestão da vida, estabelece relações de poder e constrói instituições. Para tanto, tivemos como norte a perspectiva histórico-genealógica apresentada por Foucault (1979, p. 24), na qual a idéia de emergência, em oposição à de origem, “[...] é a entrada em cena de forças, é a interrupção, o salto pelo qual elas passam dos bastidores para o teatro". Esse conceito foi nosso principal companheiro e escudeiro, pois sinaliza, a todo instante, que os objetos/discursos não são dados à priori e sim, são construções sociais datadas historicamente.

Nosso mergulho histórico entende a história não na concepção hegemônica de uma evolução de fatos ou acontecimentos cronologicamente atribuídos, mas, no sentido foucaultiano, como encontros de forças que produzem acontecimentos que alteram e alternam a lógica vigente, a percepção e os modos de ser e estar no mundo. Ou ainda como nos lembra Orlandi (1990, p. 35), tendo Foucault como norte:

[...] a história está ligada a práticas e não ao tempo em si. Ela se organiza como parâmetro às relações de poder e sentido, e não à cronologia: não é o tempo cronológico que organiza a história, mas a relação de poder [...].

Castel (1998, p. 23) também nos ofereceu argumentos a esse mergulho histórico ao pontuar que "[...] o presente não é só o contemporâneo. É também um efeito de herança, e a memória de tal herança nos é necessária para compreender e agir hoje [...]". A perspectiva histórica por ele desenvolvida não pretende:

[...] reescrever nem rever a história, mas de a reler [sic], isto é, produzir, com dados pelos quais se é inteiramente devedor aos historiadores, um outro texto que, ao mesmo tempo, tenha sua própria coerência a partir de um esquema de leitura sociológica e seja "com-possível" com o relato dos historiadores [...] (CASTEL, 1998, p. 29).

\section{UM BREVE PERCURSO HISTÓRICO}

A leitura das produções acadêmicas sobre crianças e jovens nos levou a historicizar a existência de certas instituições como Estado, família, infância e legislação e políticas públicas, tendo em vista que as mesmas sofreram transformações diversas ao longo dos anos, tanto na sua dinâmica de funcionamento quanto nos papéis exercidos pelos diversos personagens que habitavam/habitam o interior dessas instituições.

Concordamos com Barroco (2004, p. 173) quando diz que as instituições estão ligadas ao momento sócio-histórico-econômico em vigor, o que fica claro em sua afirmação:

[...] não [se] pode perder de vista o modo como os homens se apresentam ou se conformam nas/pelas relações sociais. Isso 
implica compreender como e porque determinadas formas de existência humana emergem e se mantêm em um dado período histórico.

Assim, optamos por tomar a história das relações sociais como matriz explicativa da organização familiar, entendida aqui como fruto da organização social, logo, das condições sócio-econômicas do momento. A constituição da família se dá a partir das suas condições de organização para a sobrevivência. "O trabalho, e o modo como se deu sua divisão, levou os homens a viverem de uma forma ou outra, provocando transformações nas relações que estabeleciam entre si” (BARROCO, 2004, p. 180).

De acordo com o que escreveu Deleuze no prefácio do livro A Polícia das Famílias de Donzelot (1980), é no período em que a industrialização começa a se estabelecer como modo de produção que ocorre um retraimento das redes familiares, queda da fecundidade, fim da grande família e de amplas redes de sociabilidade e ajuda econômica, em função da exploração exacerbada da mãode-obra naquele momento. Donzelot (1980) vai chamar esse processo de "crise da família", sem a qual não mais será possível a manutenção daquilo que Castel (1994) denominava "proteção por proximidade", realizada pelas redes intra-familiares ou de vizinhança, uma rede de relações propiciada pela aproximação geográfica, social e econômica.

Castel (1998) em seus estudos sobre as questões sociais nos aponta a existência, na sociedade pré-industrial, de formas de relacionamento comunitário definido como "societal", no qual a proteção era produzida pelas relações presentes na família e na convivência com vizinhos e amigos, expressa na "proteção por proximidade". Ou seja, uma "sociedade sem social". Por social, entende Castel (1998, p. 48):

[...] uma configuração de práticas especializadas a partir de uma falha nas assistências não especializadas ou primárias. [...] [Esse conceito difere-se de "societal", definido como] a qualificação das relações humanas enquanto se referem a todas as formas de existência coletiva.

Por sociedade sem social, o autor entende um sistema de regras ligando diretamente os membros de um grupo que participam de uma rede de interdependência, sem a mediação de instituições específicas. Tais sociedades priorizavam a mobilização de potencialidades para a proteção dos indivíduos desestabilizados, de forma que um órfão, por exemplo, era imediatamente inserido na rede de proteção próxima, nesse caso, uma família da redondeza.

Acreditamos que as modificações ocorridas no seio familiar estão vinculadas a um processo de ascensão do Estado como àquele que vai se responsabilizar pela garantia da proteção social, que até então funcionava num esquema de redes montadas pela aproximação física. Esses dois processos - transformações na família e ascensão do Estado - não se apresentam como distintos, sendo um a causa do outro, mas como processos paralelos, simultâneos, no qual um complementou 
o outro. As antigas redes de dependência serão substituídas por intervenções diretas do Estado, através do sistema industrial, fazendo do mesmo uma "civilização dos costumes", como nomeia Deleuze no prefácio de Donzelot (1980).

A instituição familiar foi reconfigurada em favor do capital, tendo no processo gradativo de destinação das terras cultivadas ao uso das famílias - característico da segunda grande divisão do trabalho - um marco no que diz respeito à inauguração da propriedade privada, tornando a família uma "unidade econômica da sociedade" (BARROCO, 2004).

Se, no passado, ela era pensada pela sua ascendência, pela sua história e pelo nome que carregava, agora, com o Capitalismo é a descendência que passa a ter importância, pois o corpo útil e produtivo passa a ser valorizado, disseminando uma preocupação com a produtividade futura da prole. Com isso, a mulher passa a ser convocada a assumir um papel social de mãe. Tem início a idéia de núcleo familiar, que vai se fechando na conjugalidade. O poder paterno vai perdendo sua força na medida em que passa a existir o divórcio, o que acarreta um comprometimento da subjetividade - historicamente construída - que a família encontrava no pai, enquanto "chefe" e responsável, capaz de governá-la. Desta forma, toda a rede de dependências e complementaridades que a tornava governável torna-se frágil, o que vem a possibilitar a intervenção do Estado, via judiciário.

\section{Apresentando o CenÁrio brasileiro}

Com base na lógica de proteção estatal e sua preocupação com a formação de delinqüentes, visto que os indivíduos passam a ser considerados pela virtualidade de seus comportamentos e não por infrações efetivas (FOUCAULT, 1996) surge no Brasil em 1927 a primeira lei específica para crianças e jovens, o Código de Menores, que fazia parte de um projeto de higienização dos espaços públicos, tendo em vista a disciplinarização do trabalho como resultado das mudanças econômicas e políticas da época.

De acordo com Cruz (2006), neste período encontrávamos um discurso que oscilava em defender ora a criança, ora a sociedade contra essa criança, o que significava pensar, de um lado a infância pobre, abandonada e desassistida e, de outro lado a perigosa, marginal e delinqüente.

Foi através do Código de Menores que o Estado, reorganizando a política que chamava de assistência e proteção, criou os estabelecimentos de internação. Neste período, no ano de 1942, foram criados o Serviço de Assistência do Menor (SAM) e os reformatórios que funcionariam como dispositivos de "recuperação" dos menores tidos como delinqüentes. Com uma estrutura que em muito se assemelhava ao sistema penitenciário, era um lugar onde "a disciplina e o trabalho eram os meios empregados para corrigir as condutas" (CRUZ, 2006, p. 40).

O SAM começou a ser questionado, sendo acusado pela imprensa de possuir instalações inadequadas, péssimas condições de higiene, superlotação e exploração do trabalho, e ainda, de ser ineficaz no combate à criminalidade in- 
fanto-juvenil. Esta última configurou-se como a principal crítica no sentido de impulsionar o Estado a pensar novos métodos, tendo em vista o fracasso do modelo punitivo-repressivo.

Em 1964, ano do Golpe Militar, o SAM foi extinto e surgiu a Política de Bem-Estar do Menor (PNBEM), que sofrendo forte influência do discurso médico-patologizante, afirmava o tratamento em detrimento da punição, evidenciando a produção da relação entre crime e doença. A ação corretiva naquele momento, fundamentada em métodos terapêutico-pedagógicos, passou a ser a incumbência da Fundação Nacional do Bem-Estar do Menor (FUNABEM), seguindo a proposta de um modelo educativo e não-repressivo, oscilando entre o criminoso e a vítima.

O Código de Menores de 1979 configurou-se como o segundo documento legal que veio para regulamentar a política para infância e adolescência que, embora tenha trazido mudanças na nomenclatura, como a introdução do termo "situação irregular", não produziu, de fato, uma mudança na lógica, calcada ainda na culpabilização da família pobre.

Com a constituição de 1988 foram criados diversos dispositivos legais com o objetivo de inibir as arbitrariedades que o Estado vinha cometendo no interior das Fundações Estaduais do Bem-Estar do Menor (FEBEM's). Além disso, a sociedade civil encontrava-se mobilizada através do Fórum Nacional Permanente de Entidades Não-Governamentais de Defesa dos Direitos da Criança e do Adolescente (Fórum DCA), que funcionava como rede de articulação em nível nacional, com maior autonomia com relação ao Estado, no sentido de defender a promoção dos direitos da criança e do adolescente.

Já no âmbito governamental, vale ressaltar o protagonismo político do Fórum Nacional de Dirigentes Estaduais de Políticas Públicas para a Criança e o Adolescente (FONACRIAD) que "desempenhou um significativo papel na mobilização dos governos das unidades federadas e das bancadas dos Estados nas duas casas do Congresso Nacional"' (CRUZ, 2006, p. 43 ).

Tais articulações se configuraram como o embrião que veio a desabrochar na promulgação do Estatuto da Criança e do Adolescente (ECA), em 1990, redirecionando para a política chamada de assistência e proteção a crianças e jovens, criticando o modelo punitivo-repressivo no tratamento da infância. $\mathrm{O}$ ECA ao destacar o direito da criança e do adolescente a permanecerem em suas famílias, reconhece a pobreza como um problema estrutural e não como uma condição que predispõe o rompimento de vínculos familiares, como em outrora, no Código de Menores.

Entretanto, tal redirecionamento das políticas públicas no que tange à infância e juventude, ainda que propusesse uma mudança na lógica de proteção, agora vinculada à garantia dos direitos humanos e da cidadania permanece no viés da assistência, da vitimização. Esse pensamento coincide, temporalmente, com o neoliberalismo, com a lógica do chamado Estado mínimo nas questões sociais, o que acaba por abrir um fosso entre o que há na lei e o que acontece nas 
práticas cotidianas. Dessa forma, podemos entender a razão de tantos escritos de especialistas abordarem o desrespeito aos princípios do ECA no que tange à questão do abrigamento.

\section{Políticas Públicas e PRÁticas de RePerCussão PÚbliCA No Brasil}

Por políticas públicas entendemos, como Loria (1999), o espaço de interação e interlocução entre o Estado e a Sociedade Civil (o público) na definição e regulamentação de ações, a médios e longos prazos, que afetam a vida da população e com efeitos prolongados na dinâmica de construção de valores, organização, estrutura e modos de perceber e estar no mundo. Nessa ótica, os campos do Estado e do público não podem ser encarados como sinônimos. Alerta-nos Monteiro (MONTEIRO; COIMBRA; MENDONÇA FILHO, 2006, p. 11) que:

[...] temos que repensar a relação entre Estado e políticas pública. Acreditamos que estes termos não podem ser tomados como coincidentes, visto que os domínios do Estado e do público não se justapõem, não sendo natural a relação de sinonímia entre eles. Entendemos que o público diz respeito à experiência concreta dos coletivos de forças sempre em movimento. Daí estar em plano diferente daquele do Estado enquanto figura paralisada e transcendente da modernidade.

Assim sendo, precisamos resignificar nosso papel/lugar/compromisso com a construção de uma sociedade mais justa e democrática, colocando sempre em análise nossa prática no que se refere, aqui especificamente, a garantia dos direitos de crianças e adolescentes com relação à convivência familiar e comunitária. Possibilitar que grande parte de mulheres-mães-pobres não precisem recorrer ao abrigamento como meio de sobrevivência, como medida de proteção.

Na contramão das políticas públicas, as atividades de repercussão pública se caracterizam pela fragilidade da participação da sociedade civil nas discussões e na transformação da realidade social, apresentando impacto social imediato na vida da população, mascarando a realidade.

Em outras palavras, práticas que, longe de operarem reformas políticas concretas no sentido da reversão do quadro de miserabilidade e injustiça social que assola a população brasileira, investem em programas assistencialistas e caritativos que ratificam e perpetuam o Brasil de duas faces: uma pobre e outra rica.

Nessa ótica, podemos inserir a política de adoção que incentiva a destituição do poder familiar ainda nos primeiros meses de vida com o discurso de proteção. Cabe ressaltar que as pesquisas revelam que a maioria das crianças abrigadas tem família e que ali permanecem em função da precariedade das condições das redes de proteção às quais estão filiadas.

Ainda nessa vertente, Scheinvar (2001, p. 25) em sua tese de doutorado, O Feitiço da Política Pública, muito bem passeia pelas redes de assistência que tecem o Estado Brasileiro e esclarece-nos: 
[...] a formulação política e a gestão pública, são conceitos interdependentes, não há descontinuidades entre eles. Há sim, um discurso formal que oculta os princípios norteadores do Estado, os quais, no entanto, se tornam patentes através das práticas [discursos] das políticas públicas.

Acrescenta-nos ainda a autora que não podemos falar em incompetência do Estado Brasileiro no trato às questões da menoridade, mas sim, em ações firmemente erguidas, no sentido da garantia à violação dos direitos da criança e do adolescente. Isto é, na construção de um projeto, de um discurso político coerente e competente na produção da exclusão social.

[...] a história da assistência no Brasil é uma história perversa em que, ao retirar do povo os recursos de seu trabalho e torná-lo pobre, se criam mecanismos para conceder-lhe migalhas de sua riqueza sob a forma de doação, enaltecendo os doadores e submetendo aqueles que passam a sentir gratidão e até vergonha pelo que recebem, por se sentirem incapazes de se abastecer, sem perceber que é com o seu esforço que as elites enriquecem e constroem a sua bondade (SCHEINVAR, 2001, p. 80).

\section{OS DISCURSOS DOS ESPECIALISTAS}

Pode a prática de um especialista ser uma forma de governo? A resposta é positiva, pois suas práticas exercem o que Foucault (1979) chama de "governamentalidade", um conjunto formado pelas instituições, procedimentos, análises e reflexões, cálculos e táticas que permitem exercer esta forma bastante específica e complexa de poder, que tem por alvo a população. O autor prossegue:

Se o Estado é hoje o que é, é graças a esta governamentalidade, ao mesmo tempo interior e exterior ao Estado. São as táticas de governo que permitem definir a cada instante o que deve ou não competir ao Estado, o que é público ou privado do que é ou não estatal, etc.; portanto o Estado, em sua sobrevivência e em seus limites, deve ser compreendido a partir das táticas gerais da governamentalidade (FOUCAULT, 1979, p. 292).

Assim, o envolvimento político de quem escreve sobre o tema não é meramente opcional, é inerente ao trabalho, às praticas que se referem ao abrigamento, posto que estas são atravessadas por modelos de psicologia da infância, "políticas econômicas do município, pela história da assistência brasileira, pelos conflitos sociais, etc." (NASCIMENTO, MANZINI; BOCCO, 2006, p. 16).

Segundo Scheinvar (2004) os direitos sociais são de responsabilidade do poder público, não se pode transferir esta responsabilidade. Mas não quer dizer, no entanto, que só a ele caiba assinalar quais os problemas, as formas para enfrentá-los e a sua execução. Contudo, há um histórico isolamento entre governo e sociedade civil no que corresponde à discussão dos direitos e dos caminhos para 
sua implementação e garantia. Os discursos dos especialistas que trabalham com as questões referentes ao abrigamento caem na mesma esfera de distanciamento quando se isentam de sua responsabilidade e apenas acusam o Estado, como se este fosse uma entidade surgida do nada, de não cumprir seu papel.

Muitos dos trabalhos levantados culpabilizam a família pelo rompimento dos vínculos, ou mesmo ao abrigo, sem perceber que todos esses atores fazem parte de uma complexa e pretensa rede, que no cenário brasileiro ensaia passos para se tornar uma realidade que garanta os direitos de todos. Fugindo dessa visão majoritária, encontramos poucas falas dos pesquisadores destacando tanto a importância das políticas públicas quanto as suas práticas de especialistas como um caminho a se repensar o abrigamento.

\section{CONSIDERAÇões FinAis}

O poder judiciário enquanto um dispositivo de controle social é aqui pensado como uma relação de continuidade com a engrenagem disciplinar posta em ação pelo higienismo, sendo convocado a produzir sujeitos úteis e dóceis no capitalismo moderno. Tivemos como objetivo, no presente artigo, colocar em análise a produção de subjetividade pela intervenção do Estado, via legislações e políticas públicas, e a conseqüente redefinição dos valores familiares. Esses dois processos concomitantes promovem a passagem de um funcionamento em rede intrafamiliar para um modelo judicialmente regulamentado, com suas falhas e fragilidades.

Vimos que a falência de um modelo de família voltado para o pai enquanto "chefe de família" é concomitante à inauguração desse Estado-interventor, que vai promover uma série de políticas, regulamentando as relações familiares, até então constituídas por redes formadas pela via da aproximação, seja ela econômica, social e/ou física (vizinhança). No Brasil, a intervenção estatal tem o caráter assistencialista e caritativo, se configurando em políticas de repercussão pública. Afinal, o processo de normalização da sociedade brasileira é marcado pela singular combinação da norma com a repressão. Assim, pudemos observar, através das leituras das produções escritas sobre a questão do abrigamento, que as políticas voltadas para a proteção de crianças e adolescentes têm, tradicionalmente, um viés caritativo-assistencial

Embora o surgimento do ECA proponha uma mudança de paradigma da proteção à infância e juventude, vemos que, na prática, a lógica repressiva e voltada para a culpabilização da família pobre, agora colocada em termos de "situação de risco", no tratamento da infância e da adolescência se mantêm no interior dos estabelecimentos, além de aparecerem, com freqüência, nos discursos dos especialistas que escrevem sobre essa temática. Desta forma, e porque tomamos a idéia de "rede" não como um "ente" que está dado, mas como algo em constante construção e articulação, acreditamos que o funcionamento das redes de proteção para crianças e adolescentes é um trabalho a ser feito não só pelo Estado, mas por nós, sociedade civil, e profissionais e especialistas que estão inseridos no interior dos abrigos, onde podem garantir e reafirmar, nas práticas cotidianas, a nova lógica de proteção. 


\section{Notas}

1 Essa pesquisa integra o Programa de Intervenção Voltado às Engrenagens e Territórios da Exclusão Social (PIVETES), desenvolvido pelo Departamento de Psicologia, pelo Laboratório de Subjetividade e Política (LASP) e pelo Serviço de Psicologia Aplicada (SPA) da Universidade Federal Fluminense (UFF). Conta com o apoio da FAPERJ e do PIBIC/CNPq através de bolsas de Iniciação Científica

\section{REFERÊNCIAS}

BARROCO, S. M. S. A família fetichizada na ideologia educacional da sociedade capitalista em crise: uma questão para a psicologia. In: DUARTE, N. (Org.). Crítica ao fetichismo da individualidade. Campinas: Autores Associados, 2004. p. 169-194.

BARROS, R. B. de. Grupo: a afirmação de um simulacro. Porto Alegre: Sulina/ UFRGS, 2007.

BRASIL. Estatuto da Criança e do Adolescente. Lei Federal 8.069/90 de 13.07.1990. Disponível em: http://www.planalto.gov.br/ccivil/LEIS/L8069.htm. Acesso em: 12 nov. 2008.

Código de Menores. Decreto N. 17.943 A - de 12 de outubro de 1927. Disponível em: http://www.planalto.gov.br/ccivil_03/decreto/1910-1929/ D17943A.htm. Acesso em: 14 nov. 2008.

. Constituição (1988). Disponível em: http://www.planalto.gov.br/ccivil_ 03/Constituicao/Constitui\%C3\%A7ao.htm. Acesso em: 12 nov. 2008.

CASTEL, R. Da indigência à exclusão, a desfiliação. Precariedade do trabalho e vulnerabilidade relacional. In: LANCETTI, A. (Org.) SaúdeLoucura. São Paulo: Hucitec, 1994. v. 4, p. 22-48.

. As Metamorfoses da Questão Social. Petrópolis/RJ: Vozes, 1998.

CRUZ, L. R. (Des)articulando as políticas públicas no campo da infância: implicações da abrigagem. Rio Grande do Sul: EDUNISC, 2006.

DELEUZE, G. Prefácio. In: DONZELOT, J. A Polícia das Famílias. Rio de Janeiro: Graal, 1980. p.1-8.

DONZELOT, J. A Polícia das Famílias. Rio de Janeiro: Graal, 1980.

FOUCAULT, M. Microfísica do Poder. Rio de Janeiro: Graal, 1979. . A verdade e as formas jurídicas. Rio de Janeiro: NAU, 1996. 
LORIA, C. Políticas Públicas y Reforma Del Estado. In: BHATTACHARJEA, S. (Comp.). Infancia y Política Social. México: Universidad Autónoma Metropolitana/UNICEF, 1999. p.19-52.

MONTEIRO, A., COIMBRA, C. M. B., MENDONÇA FILHO, M., Estado democrático de direito e políticas públicas: estatal é necessariamente público? Psicologia\& Sociedade, Porto Alegre, v.18, n. 2, p. 7-12, maio/ago. 2006.

NASCIMENTO, M. L.; MANZINI, J. M.; BOCCO, F. Reinventando as práticas psi. Revista Psicologia\& Sociedade, Porto Alegre, v.18, n. 1, p. 15-20, jan./abr. 2006.

ORLANDI, E. Terra à Vista: discurso do confronto, Velho e Novo Mundo. São Paulo: Cortez/Unicamp, 1990.

SCHEINVAR, E. O Feitiço da Política Pública. 2001. Tese (Doutorado)Universidade Federal Fluminense, Niterói, 2001.

. Tensões, rupturas e produções na relação entre Conselho Tutelar e a escola .In: SCHEINVAR, E.; ALGEBAILE, E. (Org.). Conselhos Participativos e Escola. Rio de Janeiro: DP\&A, 2004. p.135-166.

Recebido em: abril de 2009

Aceito em: maio de 2009 